\title{
Effect of antenatal administration of thyrotrophin releasing hormone on fetal flow velocity waveforms
}

\author{
Rekha Bajoria, Konstantinos D Stagiannis, Nicholas M Fisk
}

\begin{abstract}
Aim-To determine whether antenatal administration of thyrotrophin releasing hormone (TRH), to promote lung maturation, alters blood flow through the fetal middle cerebral, umbilical artery, or ductus arteriosus and through the maternal uterine arteries.

Methods-The effect of transplacentally administered TRH on the fetal circulation was prospectively evaluated in 30 patients between 24 and 34 weeks' gestation. TRH $(400 \mu \mathrm{g})$ was given to the mother intravenously either as a bolus or an infusion. Fetal effects were determined by measuring the maximum velocity and pulsatility index (PI) in middle cerebral artery, ductus arteriosus, uterine artery and umbilical artery Doppler waveforms. Measurements were made immediately before, and 10 and 60 minutes after maternal TRH administration.
\end{abstract}

Results-Intravenous injection of TRH had no significant effect on PI in the uterine, umbilical, or middle cerebral artery and the ductus arteriosus within $60 \mathrm{~min}$ utes of administration in either group.

Conclusion-The antenatal use of TRH in conjunction with steroids for fetal lung maturity does not affect utero-placental or fetal haemodynamic variables, as measured by Doppler. These findings, therefore, do not support the suggestion that antenatal intravenous administration of TRH either as bolus or infusion may have immediate adverse vascular effects in the fetus.

(Arch Dis Child 1997;77:F127-F130)

Keywords: thyrotrophin releasing hormone; fetal middle cerebral artery; ductus arteriosus; utero-placental circulation; fetal Doppler

Institute of Obstetrics and Gynaecology, Royal Postgraduate Medical School,

Queen Charlotte's and

Chelsea Hospital, Goldhawk Road,

London W6 0XG

R Bajoria

K D Stagiannis

N M Fisk

Correspondence to: Dr Rekha Bajoria. email: r.bajoria@rpms.ac.uk

Accepted 3 April 1997
Respiratory distress syndrome (RDS) is a major cause of neonatal mortality and morbidity. ${ }^{1}$ Transplacental glucocorticoids reduce the incidence of RDS by only $50 \%{ }^{2}$ and attention has now focused on antenatal administration of thyrotrophin releasing hormone (TRH) together with glucocorticoids to enhance surfactant synthesis and release. ${ }^{3}$ Metaanalysis shows that this strategy significantly reduces the incidence of RDS, the need for oxygen therapy, and the frequency of bronchopulmonary dysplasia. ${ }^{4}$
Apart from its hypophysiotrophic effect, TRH functions as a ubiquitous neurotransmitter, and is known to cause cerebral haemodynamic effects in experimental animals and in humans, ${ }^{56}$ seemingly via sympathetic activation and increased catecholamine production. ${ }^{78}$ Before TRH becomes widely used in clinical practice, it is important to know whether it influences fetal blood flow. Given the increasing use of Doppler monitoring in pregnancies at risk of preterm delivery, the haemodynamic effects of maternally administered TRH need to be determined. This is particularly important as TRH increases maternal blood pressure ${ }^{9}$ and suppresses endogenous prostaglandin synthesis, ${ }^{10}$ both of which are essential for regulation of ductal patency. As the rationale behind antenatal use of TRH for enhancement of fetal lung maturation is based on the assumption that it crosses the placenta freely to stimulate fetal pituitary-thyroid axis, ${ }^{11}{ }^{12}$ we speculate that such treatment may also cause ductal constriction and reduced placental perfusion. To test this hypothesis, we studied the effect of maternally administered TRH on uterine artery (UPA), fetal middle cerebral artery (MCA), ductus arteriosus (DA) and umbilical artery (UA) using colour Doppler. Furthermore, as the findings of the recent largest, multicentric double blind trial ${ }^{13}$ raised concern that the beneficial effect of antenatally administered TRH may depend on its mode of administration, we also compared the effect of TRH on fetal haemodynamics when given intravenously as a bolus or as infusion.

\section{Methods}

In this prospective observational study, fetal haemodynamic changes were determined in 40 mothers following antenatal administration of TRH. The study was conducted in a tertiary referral centre in 1994.

Patients with singleton fetuses between 24 and 34 weeks of gestation who where at risk of preterm delivery and in whom TRH administration was clinically indicated, were recruited. The gestational age was determined by ultrasound scan between 18 and 20 weeks. Mothers with multiple pregnancy, antepartum haemorrhage, pre-eclampsia or evidence of fetal compromise did not enter the study. Fetal wellbeing was assessed clinically by cardiotocography and fetal growth and liquor volume on ultrasonographic examination. Patients already in well established labour (cervical dilatation $>$ $3 \mathrm{~cm}$ and/or uterine contractions $>1$ in 10 
Table 1 Clinical findings and perinatal outcome

\begin{tabular}{llll}
\hline & TRH (bolus) (n=14) & TRH (infusion) (n=16) & P value \\
\hline $\begin{array}{l}\text { Maternal age (years) } \\
\text { Parity }\end{array}$ & $28.5(18$ to 39$)$ & $32(21$ to 36$)$ & NS \\
Gestational age: & $2(0$ to 7$)$ & NS \\
$\quad$ At entry to study (weeks) & $30.8(27$ to 34.3$)$ & $30.2(26$ to 34.3$)$ & NS \\
$\quad$ At delivery (weeks) & $38.0(31.4$ to 40.5$)$ & $36.6(28$ to 41.2$)$ & NS \\
Mode of delivery: & 10 & 10 & NS \\
$\quad$ SVD & 6 & 4 & NS \\
$\quad$ LSCS & $2985(1125$ to 3904$)$ & $2814(1024$ to 3528$)$ & \\
Birthweight (g) & $8(6$ to 10$)$ & $9(6$ to 9$)$ & NS \\
Apgar score at: & $10(8$ to 10$)$ & $10(9$ to 10$)$ & NS \\
$\quad$ 1 min & $7.237(7.18$ to 7.30$)$ & $7.305(7.09$ to 7.4$)$ & NS \\
$\quad$ 10 min & 4 & 6 & \\
Cord arterial pH & 3 & 4 & 2 \\
RDS: & 1 & & \\
$\quad$ Mild & & & \\
$\quad$ Severe & & &
\end{tabular}

minutes), those with clinical evidence of thyroid dysfunction, and those receiving tocolytic or antihypertensive medication were not recruited. None of the fetuses had evidence of structural or chromosomal abnormalities. All patients received a single dose of $12 \mathrm{mg}$ betamethasone intramuscularly before entering the study. All patients had a contemporaneous growth scan and only one fetus studied was small for gestational age. One patient in the infusion group and two in the bolus group had spontaneous rupture of membranes before study entry: in all three the amniotic fluid index was $>4 \mathrm{~cm}$. All women gave written informed consent to the additional Doppler examination, as approved by the hospital ethics committee.

Each patient received $400 \mu \mathrm{g}$ TRH. Two modes of administration have been reported before-bolus and infusion - and in our centre the mode of administration was at the discretion of the attending physician. In some cases $\mathrm{TRH}$ is given as an intravenous bolus, and in others as an infusion over 30 minutes in $50 \mathrm{ml}$ of physiological saline. Both modes of administration were studied. Doppler measurements were made immediately before maternal administration of TRH and subsequent assessments were made at 10 and 60 minutes after the beginning of the bolus or infusion. In all cases only the first dose of TRH administration was studied.

The uterine artery, umbilical artery, middle cerebral artery and ductus arteriosus were evaluated by colour pulsed Doppler imaging (Acuson XP10, 3.5 MHZ curvilinear transducer, Acuson, Mountain View, California, USA), using a $2 \mathrm{~mm}$ sample volume. The flow velocity waveform was optimised by using the smallest possible angle of insonation $\left(<50^{\circ}\right)$ and only wave forms with a clear outline were accepted. The angle independent pulsatility index (PI) (Peak velocity-end diastolic velocity/ mean velocity) was measured using an onscreen cursor for each waveform. Peak systolic or maximum blood velocity (Vmax) was also determined. The mean value of three consecutive flow velocity waveforms were used for subsequent analyses. All measurements were made during fetal apnoea, with mothers in a semirecumbent position. Doppler waveforms from the middle cerebral artery were obtained in close proximity to the greater wings of the sphenoid. ${ }^{14}$ The ductus arteriosus was visualised either in the short or longitudinal axis, depending on fetal orientation and the sample volume placed at the junction of the descending aorta and the ductus. ${ }^{15}$ Uterine artery waveforms were obtained by placing the sample gate to cover the entire lumen of the artery about $1 \mathrm{~cm}$ from the site of crossover of the external iliac and main uterine artery. ${ }^{16}$ For each patient, waveforms were obtained on one side only .

All Doppler ultrasonographic measurements were performed by one operator (KS). For each Doppler measurement, the mean values of the fetal and uterine arteries were calculated and used for further analyses. The mean coefficient of variation for the PI and maximum velocity measurements were $<14 \%$. Parametric data were expressed as means and $95 \%$ confidence intervals with non-parametric data as medians and ranges. Two way analysis of variance was used to compare values before, during, and after TRH administration to compare changes between groups. Regression analysis was used to test for associations between Doppler parameters and gestational age. A P value of $<0.05$ was considered significant. As ductal constriction is defined as a PI of $<1.9$; a trial of 12 patients would have a power of $90 \%$ at the $5 \%$ level of significance to detect a 0.7 change in PI, which would be sufficient to show ductal constriction.

\section{Results}

Of 40 patients studied, 10 were excluded because Doppler waveforms could not be obtained after treatment: in three, because of increasing uterine activity, in four due to technical difficulties, and in a further three because patients found the procedure uncomfortable. In 30 patients where a complete data set was obtained, 16 received TRH as a bolus and 14 as an infusion. Clinical features of both groups are shown in the table 1. Essentially, the maternal age, gestational age at recruitment, delivery, birthweight, Apgar score and the incidence of RDS were similar in both groups. At time of the study, one fetus in the bolus group had intrauterine growth retardation with oligohydramnios (growth along 10th centile; amniotic fluid index $<4 \mathrm{~cm}$ ), with no evidence of redistribution. The median time interval between steroid injection and Doppler studies was 40 minutes (range 20-120).

The baseline PI of uterine artery and fetal vessels (MCA, DA, and umbilical artery) were all within $2 \mathrm{SD}$ of the mean for gestational age for appropriately grown fetuses. There was no significant change in the pulsatility index and maximum flow velocity of MCA and DA during and after intravenous TRH administration as a bolus or as an infusion (fig 1). Similarly, no significant effects were found in the PI for the uterine artery and umbilical artery before and after treatment in either group (fig 2).

\section{Conclusion}

This study indicates that antenatal administration of TRH either as bolus or infusion has no 

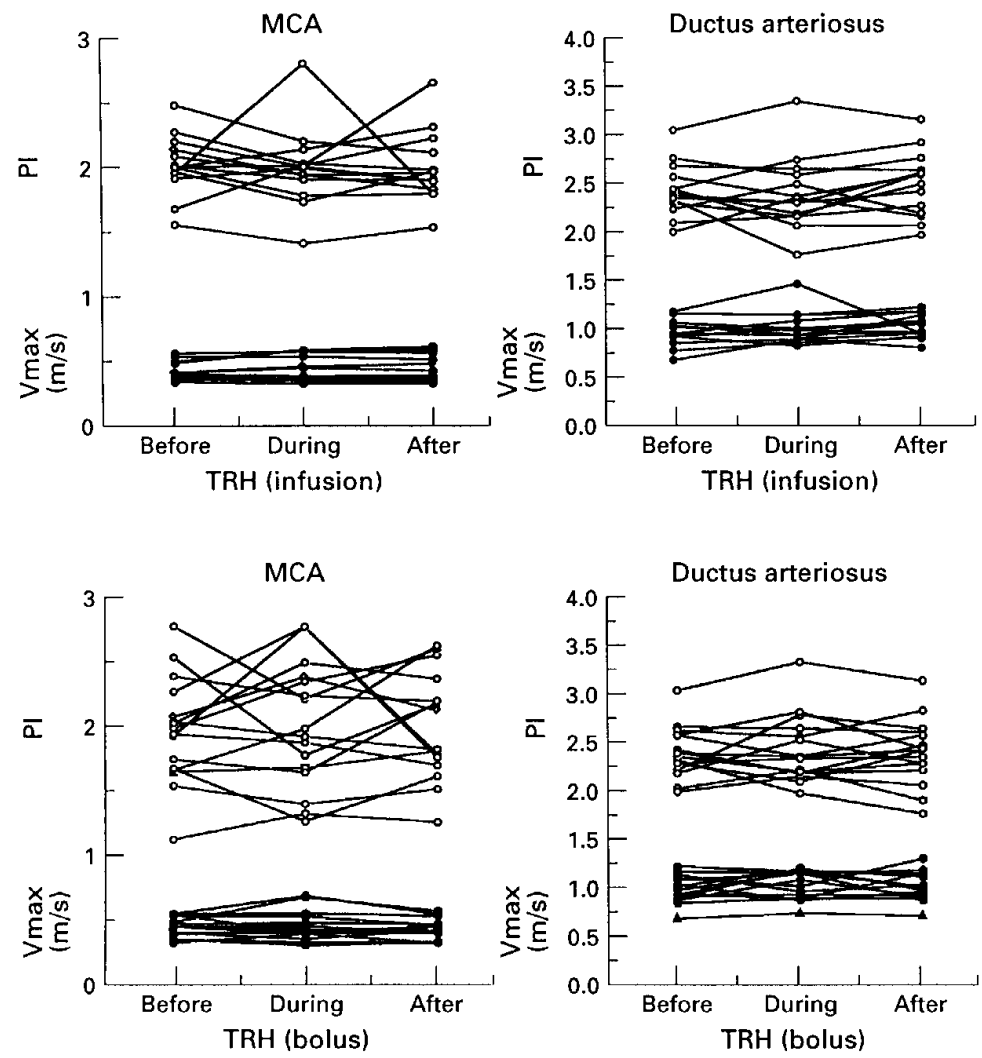

Figure 1 Mean PI (-O-) and maximum flow velocity (M/seconds) of fetal (-O-) middle cerebral artery, and ductus arteriosus before, during, and after TRH treatment either intravenously or as a bolus. No significant difference was seen in the PI before or after treatment either within the groups or between them.
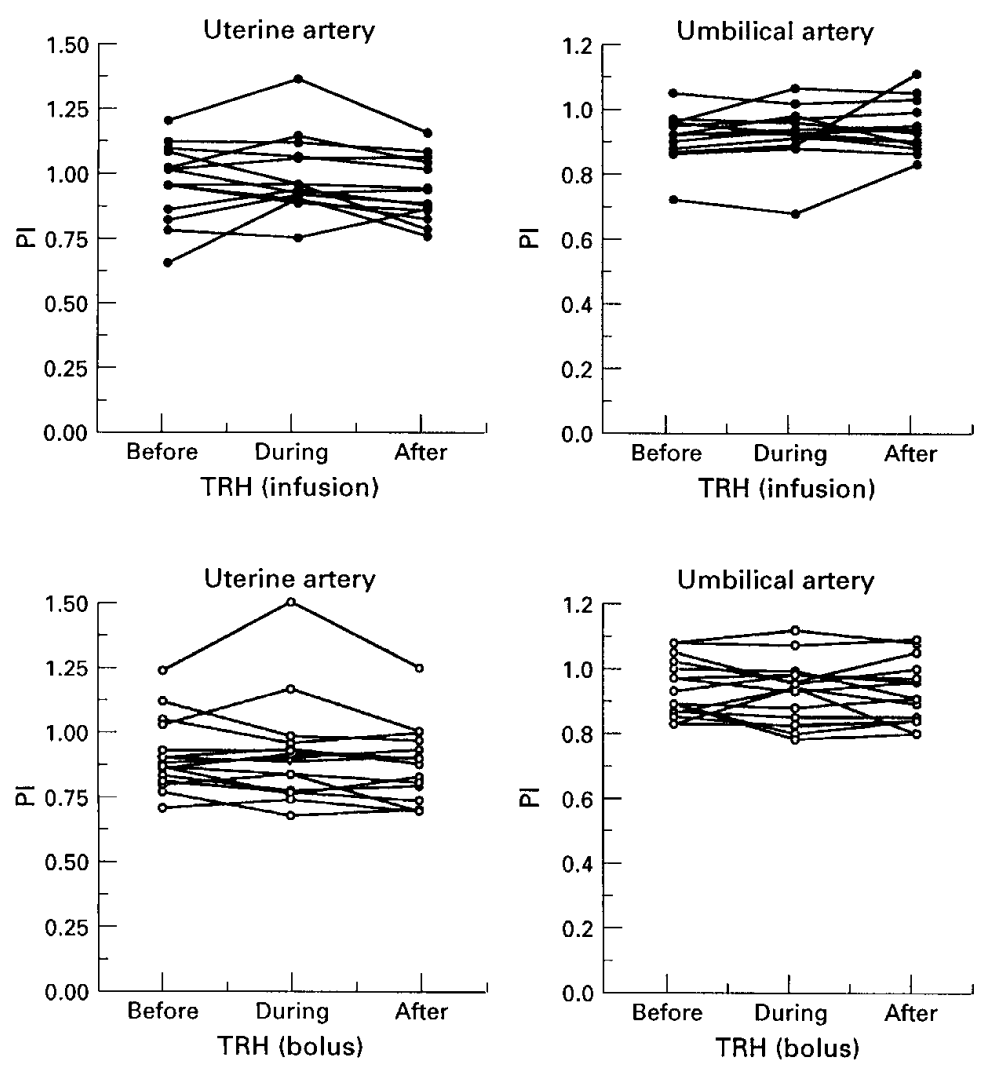

Figure 2 Mean PI of uterine artery, and umbilical artery before, during, and after TRH treatment as an intravenous infusion (-O-) or as a bolus(-0-). No significant difference was seen in the PI either before or after treatment with TRH. discernible effect on utero-placental perfusion and fetal blood flow through the umbilical, cerebral, and ductal circulation. We used the indices of PI and Vmax in Doppler flow velocity waveforms from these vessels to determine the effect of TRH. These parameters, however, provide limited information because they are indirect methods of determining changes in blood flow. Direct methods of quantifying volume flow were not used, as they are generally considered to be inaccurate due to cumulative poor reproducibility of vessel diameter, estimated weight, and velocity. Moreover, PI and maximum velocity have been widely used as reproducible parameters in clinical practice and in several research studies to determine the effect of prostaglandin synthase inhibitors on fetal vasculature. ${ }^{14} 15$

Our data suggest that the increase in cerebral blood flow seen in adults ${ }^{17}$ after TRH does not occur in fetuses. Similarly, direct administration of TRH to the fetal lamb improves cardiovascular function at birth secondary to increased circulating concentrations of catecholamines. ${ }^{6}$ In contrast, our study showed no effect of transplacental TRH on fetal blood flow. A recent study in human fetuses similarly showed that intravenous infusion of TRH fails to alter fetal blood flow through the middle cerebral artery. ${ }^{18}$ Those authors found a significant alteration in cardiac flow velocity 45 minutes after TRH administration as an intravenous infusion, which may have been an effect of TRH mediated fetal thyroxine release rather than of TRH itself. In our study we attempted to record the direct effect of TRH on fetal cerebral haemodynamics by measuring the PI at 10 minutes and again at one hour after TRH administration. We chose this time period because the maximum placental transfer of TRH is expected to occur within $10 \mathrm{~min}$ utes of administration due to its half life of 5.5-7 minutes. $^{19}$

TRH increases peripheral resistance, presumably due to the release of catecholamines ${ }^{8}$ and therefore might affect uterine blood flow. However, we failed to demonstrate any change in the uterine artery blood flow after prenatal treatment with TRH. One explanation for this may be that TRH causes a transient rise in the maternal blood pressure which is not sustained long enough ${ }^{9}$ to alter uterine artery blood flow. TRH can cross the placenta and inhibit endogenous prostaglandin secretion, which is essential for maintenance of ductal patency ${ }^{19}$ and therefore might also affect fetal ductal flow. We also failed to observe any change on fetal ductal blood flow following intravenous administration of TRH. Failure to show a change in fetal haemodynamics after administration of TRH might possibly be attributed to concomitant steroid use. Animal studies indicate that glucocorticoids can constrict the ductus arteriosus by suppressing endogenous prostaglandin production. ${ }^{20}$ Although evidence in human fetuses is inconclusive, ${ }^{21}$ a transient, mild constriction of the ductus arteriosus has been documented within 4 to 5 hours of the first injection of betamethasone or 36 hours after three to four courses of corticosteroids. ${ }^{22}$ In 
contrast in this study, all Doppler measurements were made within an hour of first dose of betamethasone. Therefore, it is unlikely that any effect of TRH on fetal waveforms was masked by concomitant steroid use. Furthermore, given the route of administration and feto-maternal ratio of $0.33,{ }^{23}$ therapeutic concentrations of steroids are unlikely to have been attained in the fetal circulation within $60 \mathrm{~min}$ utes of maternal administration.

The lack of physiological response of the fetus to TRH could be due to one of the following reasons. Firstly, TRH might be present in the fetal circulation at subthreshold concentrations. Although we did not measure the concentration of TRH in the maternal or fetal circulation, this seems unlikely because a similar dose of TRH as has been used before by other investigators, was used in our study. ${ }^{311} \mathrm{~A}$ higher fetal concentration of TRH may be needed to elicit a cardiovascular response compared with its endocrine effect. Secondly, rapid elimination of TRH from the fetal circulation might explain its lack of neurotrophic response. Although no data are available on the pharmacokinetics of TRH on the fetal circulation, the presence of relatively high concentrations of endogenous TRH in the fetal blood instead ${ }^{24}$ raises the possibility of impaired clearance. Another explanation regarding the lack of a cardiotrophic effect of TRH could be due to the inability of the human fetus to mount a catecholaminergic response between 24 to 34 weeks of gestation. Failure to demonstrate any change in fetal heart rate is consistent with this proposition. ${ }^{318}$ Notwithstanding, the human fetus is capable of mounting a response to exogenous stimuli by secreting endorphins and catecholamines from 24 weeks of gestation. ${ }^{25}$ Alternatively, if extrahypothalmic TRH receptors were absent in the human fetus, this would explain the lack of a significant effect on fetal blood flow velocity. Although no data are available on the ontogeny of TRH receptors in the human fetal central nervous system, they are present in the fetal pancreas from 15 week's gestation. ${ }^{26}$ Lastly, the minimal fetal cardiovascular effects of TRH might be due to its inability to cross the placental membrane. Antenatal administration of TRH elicits fetal thyrotrophic response, but our recent in vitro data indicate that TRH crosses the human placenta sparingly. ${ }^{27} 28$

This work was supported by a project grant from Action Research

1 Office of Population Censuses and Surveys. Birth statistics. Review of the Registrar General on births and patterns of family building in England and Wales. London: HMSO, 1992 .

2 Crowley P, Chalmers I, Keirse MJ. The effects of corticosteroid administration before preterm delivery: an overview of the evidence from controlled trials. $\mathrm{Br} \mathcal{F}$ Obstet Gynaecol 1990; 97:11-25.

3 Ballard PL, Ballard RA, Creasy RK, Padbury J, Polk DH, Bracken M, et al. Plasma thyroid hormones and prolactin in premature infants and their mothers after prenatal reatment with thyrotropin-releasing hormone. Pediatr Res 1992; 32: 673-8.

4 Crowther CA, Alfirevic Z. Antenatal thyrotropin-releasing hormone prior to preterm delivery. In: Enkin MW, Keirse MJNC, Renfrew MJ, Neilson JP, eds. Cochrane Database of Systematic reviews:Pregnancy and Childbirth Module. Version 1.2, Disk Issue 1, Record 4749. London: 1995.

5 Oturai PS, Friberg L, Sam I, Perrild H. Effects of thyrotropin-releasing hormone on regional cerebral blood flow in man. Acta Endocrinol 1992;126:243-6.

6 Seligsohn EE, Koskinen LO. Effects of alpha 2-adrenoceptor blockade and thyrotropin-releasing hormone (TRH) on the cardiovascular system in the rabbit. Acta Physiol Scand 1991;143:187-94.

7 Koskinen LO, Bill A. Thyrotropin-releasing hormone (TRH) causes sympathetic activation and cerebral vasodi(TRH) causes sympathetic activation and cerebral vasodi-
lation in the rabbit. Acta Physiol Scand 1984;122:127-36.

8 Morley JE, Tuck ML, Mayes DM, et al. Thyrotrophin releasing hormone increases plasma nor-ephinephrine in releasing hormone increases plasm
man. Horm Res 1981;114:18-23.

9 Peek MJ, Bajoria R, Shennan AH, Dalzell F, de-Swiet M, Fisk NM. Hypertensive effect of antenatal thyrotropinreleasing hormone in pre-eclampsia Lancet 1995; 345:793.

0 Koskinen LO. The influence of muscarinic and prostaglandic mechanisms on regional cerebral and peripheral blood flows and on the vascular effects of thyrotropin releasing hormone (TRH). Acta Physiol Scand 1994;152:399-406.

11 Thorpe-Beeston JG, Nicolaides KH, Snijders RJ, Butler J, McGregor AM. Fetal thyroid-stimulating hormone response to maternal administration of thyrotropin-releasing hormone. Am f Obstet Gynecol 1991;164:1244-5.

12 Crowther C, Haslam R, Hiller J, McGee T, Ryall R, Robinson J. Thyrotropin-releasing hormone: does two hundred micrograms provide effective stimulation to the preterm micrograms provide effective stimulation to the preterm fetal pituitary gland compared with four hund
grams?. Am $\mathcal{f}$ Obstet Gynecol 1995;173:719-23.

13 ACTOBAT study group: Australian Collaborative trial of antenatal TRH for prevention of neonatal respiratory disease. Lancet 1995;345:877-81.

14 Mari G, Moise KJ, Deter RL, et al. Doppler assessment of the pulsatility index of the middle cerebral artery during constriction of the fetal ductus arteriosus after indomethacin therapy. Am f Obstet Gynecol 1989;161:1528-31.

15 Rasanen J, Jouppila P. Fetal cardiac function and ductus arteriosus during indomethacin and sulindac therapy for threatened preterm labor: A randomized study. Am $\mathcal{f}$ Obstet Gynecol 1995; 173:20-5.

16 Bower S, Vyas S, Campbell S, Nicolaides K. Color doppler imaging of the uterine artery in pregnancy: normal ranges of impedence to blood flow, mean velocity an
flow. Ultrasound Obstet Gynecol 1992;2:261-5.

17 Oturai PS, Friberg L, Sam I, Perrild H. Effects of thyrotropin-releasing hormone on regional cerebral blood flow in man. Acta Endocrinol Copenh 1992; 126: 243-6.

8 Rizzo G, Capponi A, Rinaldo D, Arduni D, Romanini C. Effects of thyrotropin releasing hormone on cardiac and extracardiac flows of appropriately grown and growth retarded fetuses. Ultrasound Obstet Gynecol 1995; 6: 8-14.

19 Jackson IMD. Thyrotropin-releasing hormone. $N$ Engl f Med 1982; 306:145-55.

20 Momma K, Nishihara S, Ota Y. Constriction of the fetal ductus arteriosus by glucocorticoid hormones. Pediatr Res 1981;15:19-21.

21 Wasserstrum N, Huhta JC, Mari G, Sharif DS, Willis R, Neal NK. Betamethasone and the human fetal ductus Neal NK. Betamethasone and the human
arteriosus. Obstet Gynecol 1989; 74: 897-900.

22 Azancot-Benisty-A, Benifla-JL, Matias-A, De Crepy-A, Madelenat P. Constriction of the fetal ductus arteriosus during prenatal betamethasone. Obstet Gynecol 1995; 85: 874-6.

23 Ballard PL, Granberg P, Ballard RA. Glucocorticoid levels in maternal and cord serum after betamethasone therapy to prevent respiratory distress syndrome. 7 Clin Invest 1975; 56:1548-54.

24 Lambardi G, Lupoli G, Scopacasa F, Panza R, Minozzi M. Plasma immunoreactive thyrotropin releasing hormone (TRH) values in normal newborns. f Endocrinol Invest 1972; 1: 69-72.

25 Giannakoulopoulos X, Sepulveda P, Kourtis W, Glover V, Fisk NM. Fetal plasma cortisol and $\beta$-endorphin response Fisk NM. Fetal plasma cortisol and $\beta$-endorphin

26 Leduque P, Aratan-Spire S, Czernichow P, Dubois PM. Ontogenesis of thyrotropin-releasing hormone in the Ontogenesis of thyrotropin-releasing hormone in the
human fetal pancreas. A combined radioimmunological and immunocytochemical study. F Clin Invest 1986; 78:1028-34.

27 Bajoria R, Oteng-Ntim E, Fisk NM. Transfer of thyrotrophin releasing hormone across an in vitro model of perfused human term placenta. F Clin Endocrinol Metab 1996; 81:3476-82.

28 Bajoria R, Fisk NM. Materno-fetal transfer of thyrotropin releasing hormone: effect of concentration and mode of administration. Pediatr Res 1997;41:674-81. 